\title{
Modification of Mechanical Properties of High-Strength Titanium Alloys VT23 and VT23M Due to Impact-Oscillatory Loading
}

\author{
Mykola Chausov ${ }^{1}$, Janette Brezinová ${ }^{2, *}$, Andrii Pylypenko ${ }^{1}$, Pavlo Maruschak ${ }^{3}{ }^{\mathbb{B}}$, \\ Liudmyla Titova ${ }^{1}$ (1) and Anna Guzanová ${ }^{2}$ \\ 1 Department of Mechanics, National University of Life and Environmental Sciences of Ukraine, \\ Heroiv Oborony str.15, 03041 Kyiv, Ukraine; m.g.chausov@gmail.com (M.C.); andriy3pl@gmail.com (A.P.); \\ titovall@ukr.net (L.T.) \\ 2 Department of Engineering Technologies and Materials, Faculty of Mechanical Engineering, \\ Technical University of Košice, Mäsiarska 74, 04001 Košice, Slovakia; anna.guzanova@tuke.sk \\ 3 Department of Industrial Automation, Ternopil National Ivan Pul'uj Technical University, Ruska str. 56, \\ 46001 Ternopil, Ukraine; maruschak.tu.edu@gmail.com \\ * Correspondence: janette.brezinova@tuke.sk; Tel.: +421-55-602-3542
}

Received: 30 November 2018; Accepted: 10 January 2019; Published: 14 January 2019

\begin{abstract}
A simple technological method is proposed and tested experimentally, which allows for the improvement of mechanical properties in sheet two-phase high-strength titanium alloys VT23 and VT23M on the finished product (rolled metal), due to impact-oscillatory loading. Under impact-oscillatory loading and dynamic non-equilibrium processes (DNP) are realized in titanium alloys, leading to the self-organization of the structure. As a result, the mechanical properties of titanium alloys vary significantly with subsequent loading after the realization of DNP. In this study, the test modes are found, which can be used in the production conditions.
\end{abstract}

Keywords: high-strength titanium alloys; mechanical properties; crack resistance

\section{Introduction}

High-strength titanium alloys are used as structural materials in almost all modern load-bearing structures [1,2]. In particular, titanium alloys are used in air transportation and aerospace systems for various purposes and in special equipment products [3]. High strength, low density, high specific strength, and wide temperature range of titanium alloys can significantly reduce the mass of structures and increase the reliability of their work. At present, special titanium alloys with varying strength and, more importantly, high ductility, have been developed. These alloys include two-phase high-strength $(\alpha+\beta)$ titanium alloys VT23 $\left(\sigma_{\mathrm{us}} \geq 1150 \mathrm{MPa}, \delta=15 \%\right)$ and VT23M $\left(\sigma_{\text {us }} \geq 1100 \mathrm{MPa}, \delta=20 \%\right.$ ) [4-7]. In order to attain such enhanced mechanical properties of these two-phase titanium alloys, the developers of semi-finished products realize complex multi-stage modes of thermomechanical treatment (TMT) with different percentage ratios of $\alpha$ and $\beta$ phases and different amounts of alloying elements added [8,9]. Attention should be paid to the fact that most of the stages of complex TMT modes occur under conditions far from thermodynamic equilibrium. Therefore, as early as at the stages of manufacturing, semi-finished titanium alloys and dynamic non-equilibrium processes (DNPs) are realized in melts, which aid in the formation of unique mechanical properties of titanium alloys of the class under consideration $[9,10]$.

On the other hand, the search for new methods to improve the mechanical properties of high-strength titanium alloys already on the finished product (rolled metal) is ongoing. Here, we should highlight the promising methods associated with the influence of different energy 
fields, such as electromagnetic, ultrasonic, and force fields, which realize the chaotic dynamics in materials [11-13].

Chausov et al. were the first to propose and test a simple and effective method for realizing DNP by applying additional impulse loading on materials of different classes [14-16]. Metallophysical experiments helped to reveal [17-19] that under impact-oscillatory loading, due to the pulsed introduction of energy into aluminum alloys, armco-iron, and stainless steel, there occur self-organizing processes in materials with the formation of new spatial dissipative structures, which are connected at different scale levels and look like adiabatic bands of shear. Here, it should be noted that the conditions under which these bands are formed are fundamentally different from the conditions under which adiabatic bands of shear are formed. In particular, the deformation rates of materials are by far less than those at which the classical adiabatic bands of shear are formed. Moreover, as shown by calculations, an increase in temperature of the material, even if all the deformation work is spent on this process, cannot exceed $200 \mathrm{~K}$ [16]. This confirms once again that these processes are not associated with a significant increase in temperature.

In the process of experimenting, it was also found that with an increase in the number of pulses that affect the investigated material, there is an increase in the jump of deformation under DNP [16,17]. Accordingly, as experiments have shown, at any given degree of the preliminary static deformation, there is necessarily a critical value of the pulse $\left(F_{\text {imp.cryt. }}\right)$, under which the specimen is practically divided into two parts in the process of DNP [17]. The revealed structural transformations occur exclusively in the mode of loading (the so-called energetic formation of the structure) and upon cessation of loading, the structure can be subjected to relaxation changes. Despite such relaxation changes in the structure, each new condition of the material acquires new mechanical properties with the subsequent static stretching after the application of the particular pulse that affects the material. In this case, the essential role can be played by the exposure time after the application of such pulse, the number of pulses, as well as the sequence of given specific values of the pulses that affect the material.

In particular, there was a significant increase in the plastic properties of metals after this kind of influence. Previous experiments have also shown that impulse introduction of energy into a material can improve the characteristics of crack resistance. It is also interesting to note that when the DNP is realized due to the impact-oscillatory loading, a significant increase in plasticity does not lead to a significant decrease in strength [16-20].

The analysis of the results obtained by the authors with regard to the tests of various class materials under impact-oscillatory loading has shown that in transient modes of loading, which are realized with short pulses of additional force loads, when there occurs a mass transfer while the dissipation of energy, in the classical sense (the transformation of mechanical energy into heat), has not begun yet, the slow diffusion mechanisms of the transfer of motion and energy cannot develop fast enough. Therefore, the energy of the force pulse is transferred from the macroscopic level to a certain intermediate mesoscopic level, at which the energy left in the medium is spent on the formation of new dissipative structures. According to the authors, this process can be realized when the duration of the process of loading and the duration of the process of dissipative structure formation (internal time) are identical or nearly identical.

Lack of experimental data in this area of research makes it impossible to unambiguously answer the question of which parameters of the initial structure of the two-phase titanium alloys are most sensitive to dynamic nonequilibrium processes. Previous studies on titanium alloys of various classes have shown that, for instance, for a two-phase titanium alloy VT22 subjected to impact-oscillatory loading, the plastic deformation increases significantly — by 2.5 times as compared to the initial state, and the strength remains virtually unchanged, i.e., it does not decrease [21,22]. Metallophysical research has established a new mechanism for the formation of dissipative structures in the titanium alloy VT22 after the realization of DNP, a significant fragmentation of the structure [21,22]. Similar tests on submicrocrystalline titanium alloy VT1-0, on the contrary, have established a significant 
decrease both in plastic deformation and strength after the realization of DNP due to impact-oscillatory loading [23]. Thus, we can draw a preliminary conclusion that the positive or negative effect of DNP on changes in the mechanical properties of two-phase titanium alloys due to impact-oscillatory loading depends primarily on the initial parameters of the structure.

The purpose of this research was to evaluate the effect of impact-oscillatory loading on changes in the mechanical properties of sheet two-phase titanium alloys VT23 and VT23M, the chemical composition of which is virtually the same, but the percentage ratio of $\alpha$ and $\beta$ phases is different.

\section{Materials and Methods}

The mechanical testing technique is implemented on the basis of a modified hydraulic setup for static testing ZD-100Pu and is described in detail in [14-16]. The main idea of the proposed technique is a high-speed stretching of a material, with a high frequency $(1-2 \mathrm{kHz})$ oscillatory process superimposed on it, which corresponds to the natural frequency of the testing machine. Structurally, this is achieved in the following way: in addition to the external circuit (loadable frame of the testing machine), an internal circuit is introduced into the testing machine. The internal circuit is the simplest statically undefined structure in the form of three parallel elements that are loaded simultaneously: the central specimen and two satellite specimens (brittle samples) of different cross section made of hardened steel 65 G or U8-U12. When this structure is tensioned, the satellites are destroyed and pulsed energy is introduced into the material of the specimen under study. Satellites can be included in the work at any stage of preliminary static stretching, thus it is possible to investigate the effect of the pulsed energy introduction on the degradation of mechanical properties by observing the material damage in the process of static stretching. The average value of the force of failure of the satellite samples is $113.6 \mathrm{kN}$, dispersion of the force of failure of the satellite samples is $21.15 \mathrm{kN}^{2}$, the dispersion of the $\varepsilon_{\text {imp }}$ is $0.06 \%$. By changing the initial diameter of the satellite specimens, it is possible to adjust the intensity of the impulse introduction of force energy into the material. For each condition, three to five specimens were tested. Static tests of specimens were carried out according to ASTM E8M-04 [24].

The mechanical properties of the alloys in the initial state are given in Table 1.

Table 1. Mechanical properties of titanium alloys VT23 and VT23M.

\begin{tabular}{cccc}
\hline \multirow{2}{*}{ Titanium Alloys } & \multicolumn{3}{c}{ Mechanical Properties } \\
\cline { 2 - 4 } & $\boldsymbol{\sigma}_{\mathbf{y s}}, \mathbf{M P a}$ & $\boldsymbol{\sigma}_{\text {us }}, \mathbf{M P a}$ & $\boldsymbol{\delta}, \boldsymbol{\%}$ \\
\hline VT23 & $980-1180$ & $1080-1280$ & 15 \\
VT23M & $1000-1150$ & $1080-1180$ & 20 \\
\hline
\end{tabular}

Mechanical tests were performed on specimens (Figure 1a) from industrial titanium sheet alloys VT23 and VT23M with a thickness of $3 \mathrm{~mm}$. The strain measurement base was $16 \mathrm{~mm}$. Figure $1 \mathrm{~b}$ shows a test specimen with initial central circular holes with a diameter of $0.8 \mathrm{~mm}$ for crack resistance investigations.

Modes of mechanical testing of specimens from alloys VT22 and VT22M are given in Table 2.

The chemical composition of the VT23M alloy is virtually the same as that of the VT23 alloy (see Table 3). However, the mode of thermal treatment is different; this fact has a significant effect on the improvement of plastic properties of the VT23M alloy, compared with the VT23 alloy (see Table 1). 


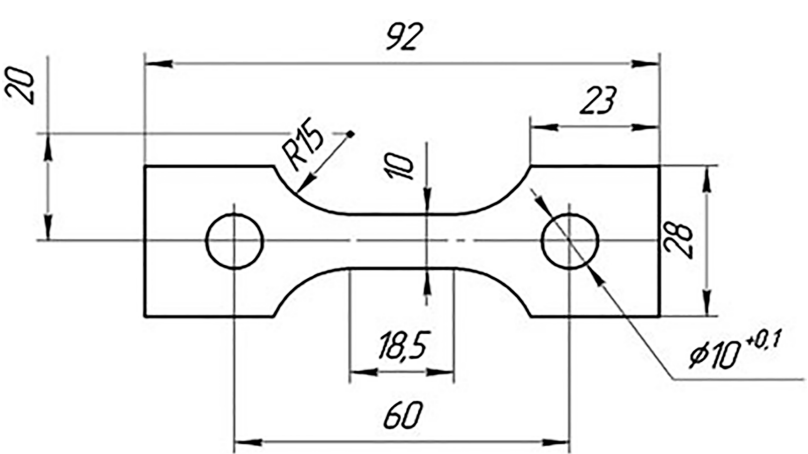

(a)

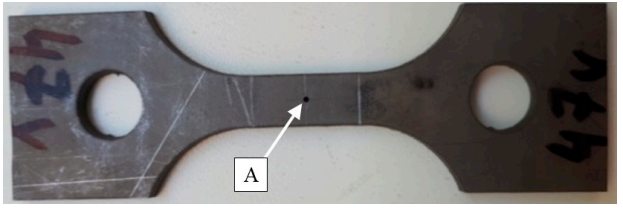

(b)

Figure 1. Specimens: for mechanical tests at static loading and DNP (a) and for crack resistance investigation (b); A-hole with a diameter of $0.8 \mathrm{~mm}$.

Table 2. Testing modes for specimens from high-strength titanium alloys VT22 and VT22M.

\begin{tabular}{|c|c|c|c|}
\hline Titanium Alloys & Scheme of Loading & $\begin{array}{c}\text { Preliminary Static } \\
\text { Deformation, } \varepsilon_{\text {stat, }} \%\end{array}$ & $\begin{array}{c}\text { Impact Loading, } \\
F_{\text {imp }}, \mathrm{kN}\end{array}$ \\
\hline \multirow{4}{*}{ VT23 } & Static tension (No. 19) & - & - \\
\hline & $\begin{array}{l}\text { Static tension-DNP-Static } \\
\text { stretching (No. 28) }\end{array}$ & 0.367 & 122 \\
\hline & $\begin{array}{l}\text { Static tension-DNP-Static } \\
\text { stretching (No. 31) }\end{array}$ & 0.322 & 125 \\
\hline & $\begin{array}{l}\text { Static tension-DNP-Static } \\
\text { stretching (No. 27) }\end{array}$ & 0.363 & 125 \\
\hline \multirow{12}{*}{ VT23M } & Static tension (No. 33y) & - & - \\
\hline & $\begin{array}{l}\text { Static tension-DNP-Static } \\
\text { stretching (No. 42y) }\end{array}$ & 0.031 & 93 \\
\hline & $\begin{array}{l}\text { Static tension-DNP-Static } \\
\text { stretching (No. 37y) }\end{array}$ & 0.025 & 76 \\
\hline & $\begin{array}{l}\text { Static tension-DNP-Static } \\
\text { stretching (No. 40y) }\end{array}$ & 0.046 & 103 \\
\hline & $\begin{array}{l}\text { Static tension-DNP-Static } \\
\text { stretching (No. 41y) }\end{array}$ & 0.034 & 106 \\
\hline & $\begin{array}{l}\text { Static tension-DNP-Static } \\
\text { stretching (No. } 2 \mathrm{y} \text { ) }\end{array}$ & 0.093 & 105 \\
\hline & $\begin{array}{l}\text { Static tension-DNP-Static } \\
\text { stretching (No. 7y) }\end{array}$ & 0.288 & 108 \\
\hline & $\begin{array}{l}\text { Static tension-DNP-Static } \\
\text { stretching (No. } 5 y \text { ) }\end{array}$ & 0.585 & 85 \\
\hline & $\begin{array}{l}\text { Static tension-DNP-Static } \\
\text { stretching (No. 4y) }\end{array}$ & 0.754 & 98 \\
\hline & $\begin{array}{c}\text { Static tension-DNP-Static } \\
\text { stretching (No. 3y) }\end{array}$ & 0.852 & 92 \\
\hline & $\begin{array}{l}\text { Static tension-DNP-Static } \\
\text { stretching (No. 39y) }\end{array}$ & 1.488 & 77 \\
\hline & $\begin{array}{l}\text { Static tension-DNP-Static } \\
\text { stretching (No. 32y) }\end{array}$ & 3.75 & 91 \\
\hline
\end{tabular}

Table 3. Chemical composition of titanium alloys VT23 and VT23M.

\begin{tabular}{ccccccc}
\hline Titanium Alloys & Fe & Cr & Mo & V & Ti & Al \\
\hline VT23 & 0.6 & 1.2 & 2.0 & 4.3 & 86.9 & 5.0 \\
VT23M & 0.7 & 1.1 & 2.2 & 4.5 & 86.7 & 4.8 \\
\hline
\end{tabular}

To estimate the percentage of $\alpha$ and $\beta$ phases in titanium alloys VT23 and VT23M in the initial state, we used $\mathrm{X}$-ray examination. X-ray examination was performed in monochromatic $\mathrm{Cu}-\mathrm{K} \alpha$ radiation on 
a DRON-UM1 diffractometer (JSC Bourevestnik, St. Petersburg, Russia). As a monochromator, a single crystal of graphite was installed on a diffracted beam. The diffractograms were taken by step scanning in the range of angles $2 \Theta 10-90^{\circ}$. The scan step was $0.05^{\circ}$ and the exposure time at a point was $3 \mathrm{~s}$. The data of the diffractometric experiment were processed using a program for full spectrum analysis of X-ray spectra from a mixture of polycrystalline phase components Powder Cell 2.4. In full-profile analysis of diffraction patterns, the texture patterns were taken into account using the March-Dollase model $[25,26]$. The correction for the intensity of any hkl maximum in this model was performed by introducing an effective repetition factor $M_{h k l}$ :

$$
M_{h k l}=\sum_{i=1}^{m}\left(\tau^{2} \cdot \cos ^{2} \varphi_{i}+\tau^{-1} \cdot \sin ^{2} \varphi_{i}\right)^{-3 / 2}
$$

where $\tau$ is the correction factor of the texture, $m$ is the crystallographic repetition factor for this family of equivalent planes $\{\mathrm{hkl}\}, \varphi$ is the smallest value of the angle between the normal to this plane (hkl), and the specified texture vector. According to Equation (1), in the absence of the texture $\tau=1$, at $0<\tau<1$, we have $M_{h k l}>1$ and the intensity of the maximum of hkl becomes greater in comparison with the non-textured specimen, and for $\tau>1, M_{h k l}<1$.

For conducting metallophysical studies, electronic scanning microscopes JEOL JSM-6610nx (JEOL Ltd., Tokyo, Japan) and REM-106I (JSC SELMI, Sumy, Ukraine) were used. The comparison of the fracture surfaces was carried out at commensurate (but not always the same) magnifications, taking into account the well-known methodological aspects [27-29]. This made it possible to establish the main laws of fracture at the macro-, meso-, and micro- levels $[30,31]$.

\section{Results and Discussion}

The results of the diffractometric study have shown (Figure 2) that in the titanium alloy VT23, $\beta$-phase occupied $43 \%$ by weight, $\alpha$-phase was $57 \%$ by weight, and in the titanium alloy VT23M, $\beta$-phase occupied $22 \%$ by weight, $\alpha$-phase was $78 \%$ by weight. Characteristically, both of the phase components in the specimens have a texture along the crystallographic direction (002). The latter may be due to the rolling of specimens or other mechanical effects applied to them.

Attention should be paid to the values of periods of the phase lattice in the investigated specimens of alloys. Thus, in the transition from the specimens of the VT23M alloy to the specimens of the VT23 alloy, the volume of the elementary cell of the alpha-Ti hexagonal lattice decreases from $34.84 \mathrm{~A} 3$ to $34.58 \mathrm{~A} 3$, and for the elementary cell of the beta-Ti cubic lattice, the volume decreases from $33.49 \mathrm{~A} 3$ to $33.08 \mathrm{~A}$ 3. Such changes may be due to the substitution of titanium atoms with atoms of a smaller atomic radius or the formation of a certain number of vacancies in crystalline lattices.

Previous experiments on specimens from the VT23 and VT23M alloys have shown that loading conditions, in which the total stress in the specimens subjected to the preliminary tension and additional pulse loading does not exceed the yield strength of the alloys, virtually do not lead to an increase in plastic deformation of the alloys during repeated static stretching. In some cases, there was even a decrease in plastic deformation by up to $10 \%$ compared with the initial state.

Therefore, the technique of further testing was as follows. The series of specimens from the VT23 and VT23M alloys, were successively loaded with static tension to an initial load of $8.0 \mathrm{kN}$ and further with a step of $2.0 \mathrm{kN}$. With these fixed static loads, the specimens were subjected to a predetermined additional force pulse load $F_{i m p}=45-50 \mathrm{kN}$. In the process of impulse introduction of energy into the alloys, the jumps of plastic deformation $\varepsilon_{\text {imp }}$ were recorded; after the realization of the DNP, the specimens were completely unloaded. Next, all the test specimens were statically stretched again until failure, and the $\varepsilon_{\text {imp }}$ parameter was used to determine the effect of the pulsed energy input on an increase in plastic deformation of the alloys in comparison with the initial state. 


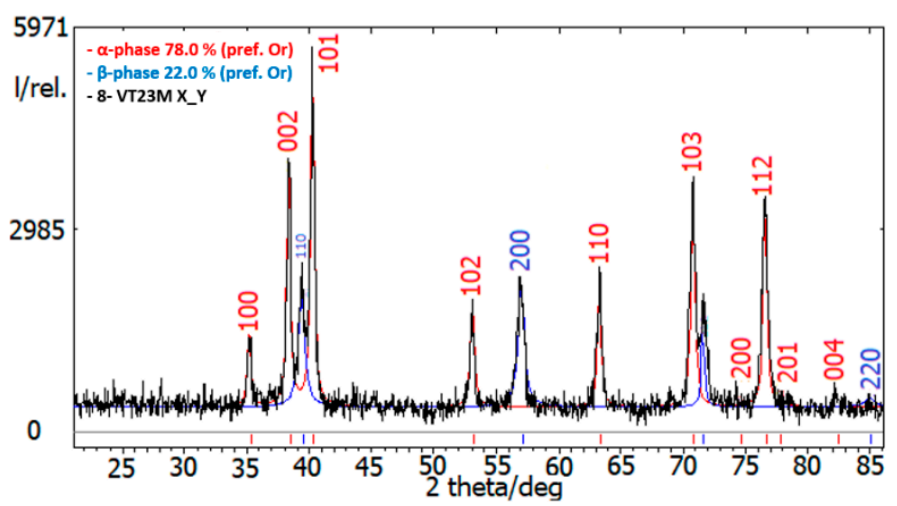

(a)

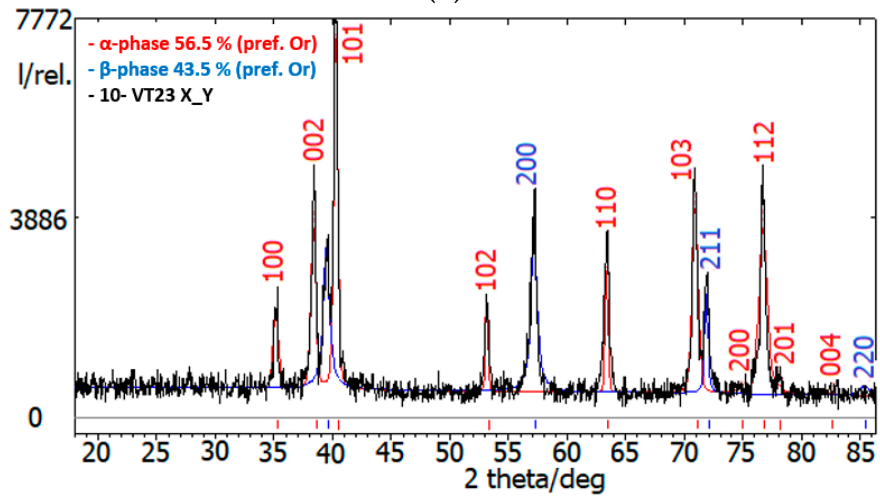

(b)

Figure 2. Results of diffractometric study on the evaluation of percentage of $\alpha$ and $\beta$ phases in the studied titanium alloys: (a) VT23M alloy ( $\beta$-phase occupied $22 \%$ by weight, $\alpha$-phase was $78 \%$ by weight); (b) VT23 alloy ( $\beta$-phase occupied $43 \%$ by weight, $\alpha$-phase was $57 \%$ by weight).

\subsection{VT23 Alloy}

\subsubsection{Effect of DNP}

Stress-strain curves of the specimens under various test conditions were recorded (Figure 3). Based on these data, their mechanical properties were determined. It was shown that for specimens after DNP, plasticity increases and the relative parameter $\lambda$ increases to $34.33 \%$, see Table 4 . It should be noted that for all deformation schemes, the conventional tensile strength remains almost unchanged and varies in the range from $1129 \mathrm{MPa}$ to $1170 \mathrm{MPa}$ under static loading.

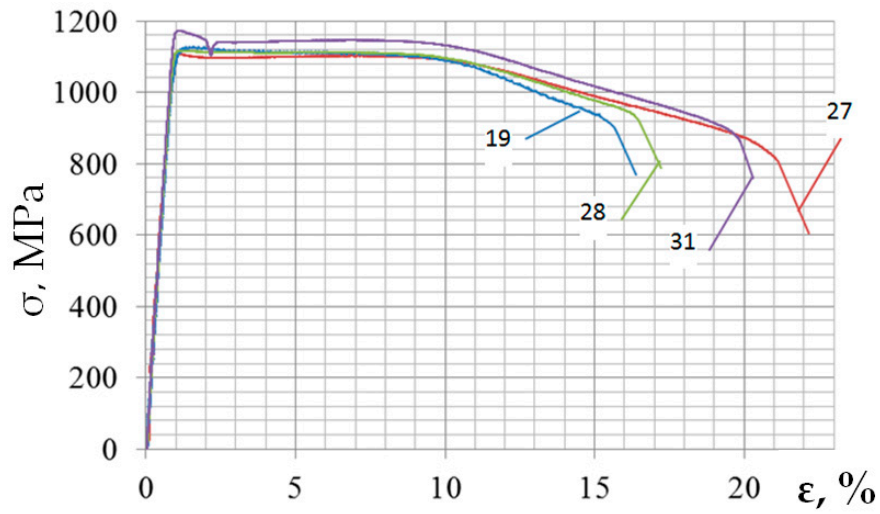

Figure 3. Stress-strain diagrams of the tested specimens from alloy VT23 (loading modes are given in Table 2). 
Table 4. Parameters of deformation and fracture of specimens from alloy VT23.

\begin{tabular}{ccccc}
\hline Alloy & Scheme of Loading & $\boldsymbol{\sigma}_{\mathbf{u}}, \mathbf{M P a}$ & Failure Strain, $\varepsilon_{\mathbf{f}}, \mathbf{\%}$ & $\boldsymbol{\lambda}=\left(\varepsilon_{\mathrm{fDNP}}-\varepsilon_{\mathrm{fst}}\right) / \varepsilon_{\mathrm{fst}}{ }^{*} \times \mathbf{1 0 0} \%$ \\
\hline \multirow{2}{*}{ VT23 } & 19 & $1129^{*}$ & 15.7 & 0 \\
& 28 & 1116 & 16.4 & 4.39 \\
& 31 & 1170 & 19.8 & 26.17 \\
& 27 & 1107 & 21.1 & 34.33 \\
\hline
\end{tabular}

${ }^{*} \varepsilon_{\text {fst }}$-failure strain of the specimen during static failure.

Figure 4 shows the generalized dependence of $\varepsilon_{\text {plast }}$ from $\varepsilon_{\text {imp }}$ for a series of tested specimens from alloy VT23. The results obtained allow us to draw two important conclusions:

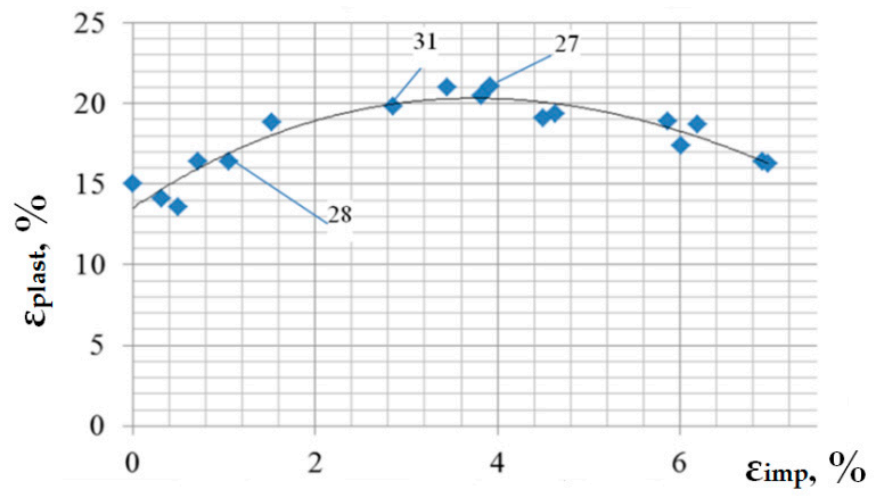

Figure 4. Dependence of plastic deformation of specimens from titanium alloy VT23 under static stretching $\left(\varepsilon_{\text {plast }}\right)$ on impulse deformation $\left(\varepsilon_{\text {imp }}\right)$ obtained under dynamic non-equilibrium processes (DNP).

Firstly, in the case when the VT23 alloy deforms plastically during the impulse introduction of energy, there is always an increase in plastic deformation under repeated static stretching compared with the initial state. Secondly, the very degree of plastic deformation in the process of impulse introduction of energy is an indicator that shows an increase in the plasticity of the alloy.

Data shown in Figure 4 allow us to justify the optimal mode of impulse introduction of energy for maximizing the plastic deformation of the VT23 alloy compared with the initial state. Conventionally, the graph can be divided into 3 sections:

Stage 1 (before $\varepsilon_{\text {imp }}=3.0 \%$ ) is the section showing an increase in the deformation of specimens with an increase in the deformation of the impulse loading.

Stage 2 (before $\varepsilon_{\text {imp }}=3.5-5.0 \%$ ) is the section of the "optimal" plastic deformation; plastic deformation of the titanium alloy VT23 can be increased by $30-35 \%$.

Stage 3 (before $\varepsilon_{\text {imp }}=5.0-7.0 \%$ ) is the section showing a decrease in the influence of DNP with an increase in the deformation of impulse loading.

\subsubsection{Fractographic Analysis of Failure of the VT23 Alloy}

The regularities in the growth of plastic deformation under the impulse introduction of energy into the VT23 alloy are confirmed by the data of the fractographic analysis of the fracture surfaces of specimens from titanium alloy VT23.

Fractures of specimens tested under deformation schemes 19 and 27, the stress-strain diagrams of which are significantly different (see Figures 5 and 6), were analyzed. The analysis of fracture surfaces of these specimens shows significant differences in their morphology. Thus, the analysis of the specimen failure under static stretching (curve 19 in Figure 3) indicates that in the central zone of the specimen, fracture occurred by the mechanism of separation, and on the near-surface sections it occurred by the mechanism of shear, with the formation of "micro-steps" and local micro-tears of the material (Figure 5a). 


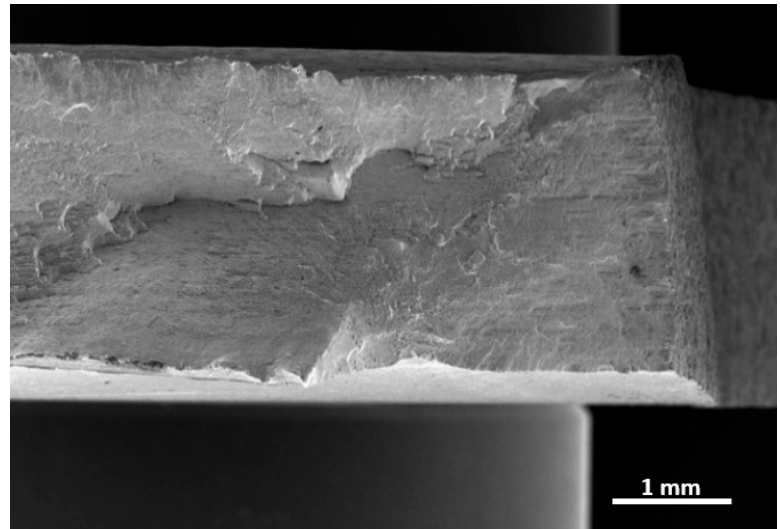

(a)

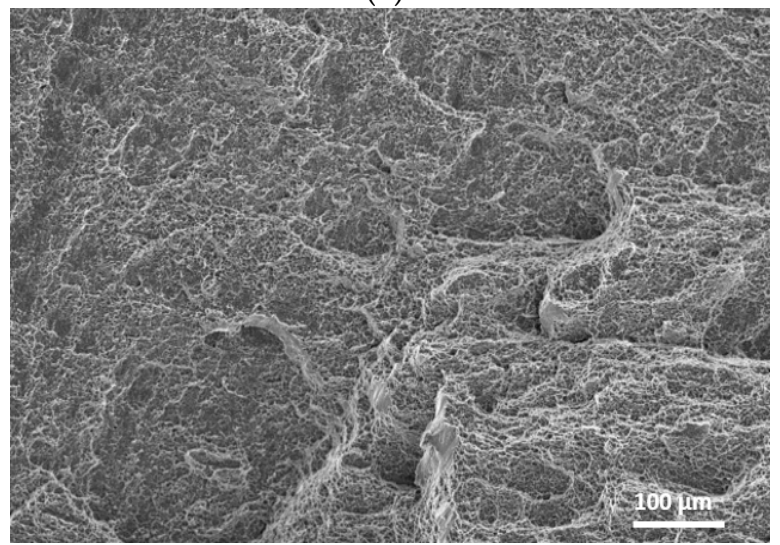

(c)

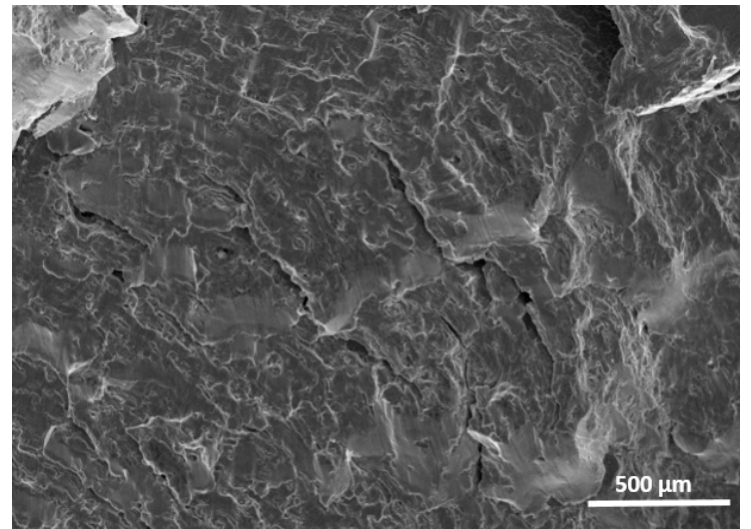

(b)

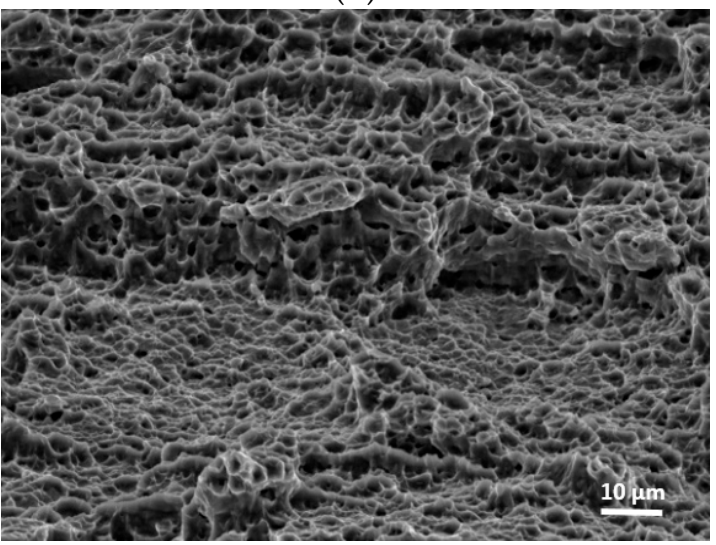

(d)

Figure 5. Fracture surface of the specimen from the VT23 alloy under static stretching (curve 19 in Figure 3) obtained at macro-(a,b) and micro-(c,d) levels.

With a small magnification, the fracture looks "flattened". With a certain assumption it can even be stated that this type of fracture is inherent in the low-energy fracture. It was found in the microanalysis that the surface was formed by a plurality of quasi facets measuring 2-5 $\mathrm{mm}$ (Figure 5b), the boundaries of which appear to be rather brittle, as evidenced by the absence of a viscous border consisting of microdimples (Figure $5 \mathrm{c}, \mathrm{d}$ ).

Figure 6 shows the fractograms of the fracture surfaces of the specimen from the VT23 alloy tested under loading scheme 27 (see Table 2), which was previously subjected to the impulse loading. It is noticeable that the fracture has significant distortions in the cross-section, indicating a significant localization of plastic strains during deformation and fracture (Figure $6 a, b)$. It should be noted that the relief indicates the presence of shear, separation, and even rotational microstrains [32-34]. In addition to the traditional microfacet relief, the longitudinal gaps (Figure $6 c, d$ ) were found in the fracture, which, in our opinion, provided for an additional resistance of the material to fracture.

These gaps were formed during the crack propagation in the direction transverse to the rolling direction of the sheet, from which the specimens were made. The shape of the microfacet is close to the circular one, which allows us to consider them as micro-dimples with a flat bottom. Thus, the fractographic features of specimen fractures indicate an improvement in the plastic properties of the VT23 alloy after the DNP realization at the microlevel. 


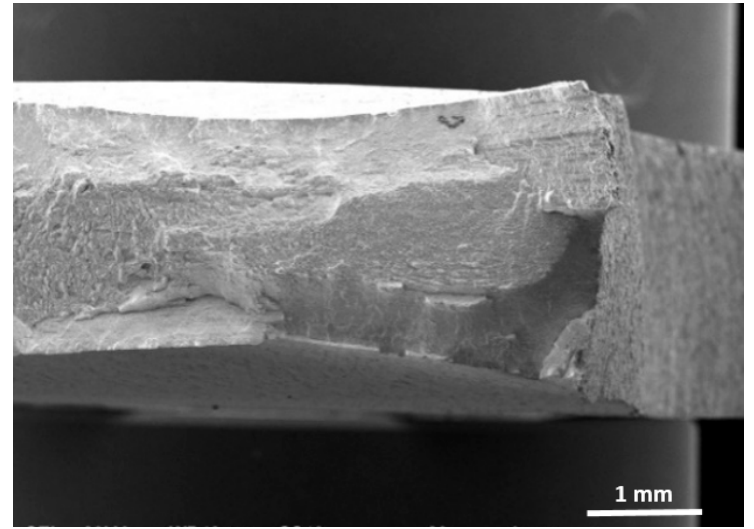

(a)

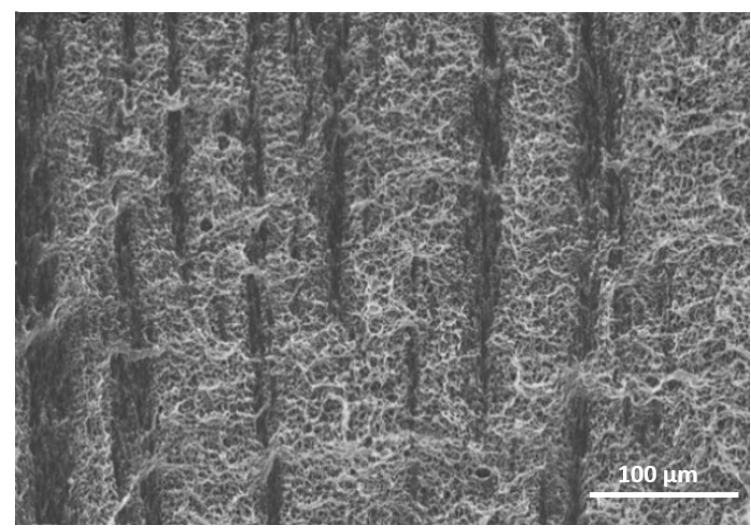

(c)

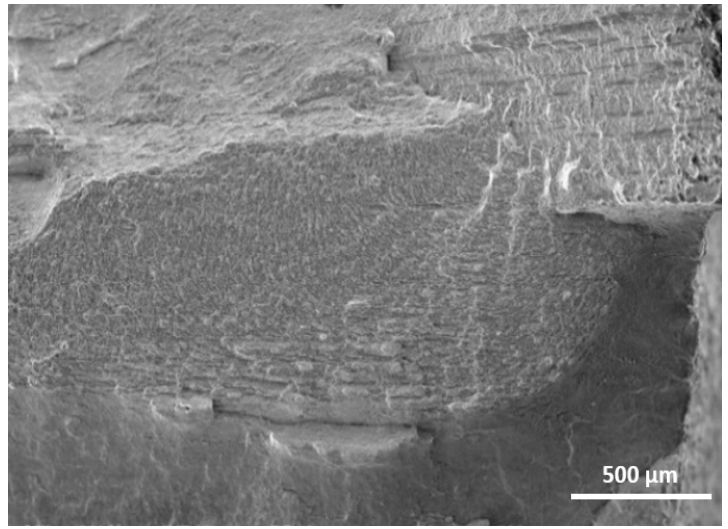

(b)

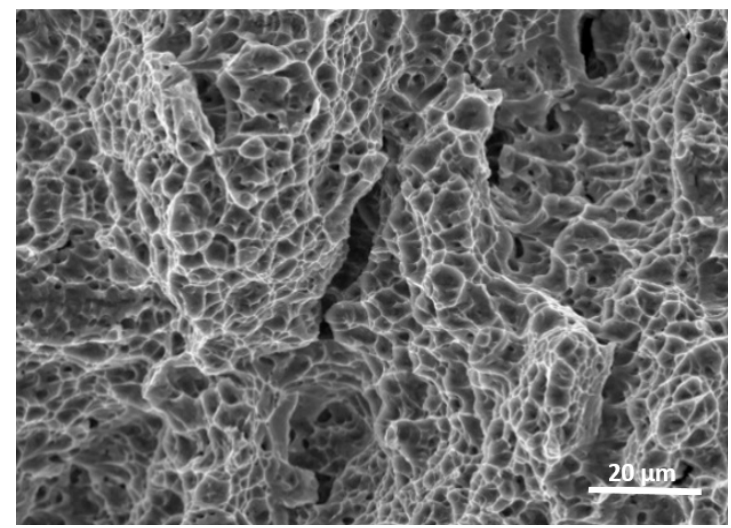

(d)

Figure 6. Fracture surface of the specimen from the VT23 alloy previously subjected to impulse loading (curve 27 in Figure 3) obtained at macro-(a,b) and micro-(c,d) levels.

\subsubsection{Alloy VT23M}

For the VT23M alloy, it was impossible to significantly increase plastic deformation after the DNP, as shown in Table 5 .

Table 5. Influence of impulse loading modes for testing specimens from the VT23M alloy on changes in the mechanical properties of the alloy.

\begin{tabular}{ccccc}
\hline Alloy & Scheme of Loading & $\boldsymbol{\sigma}_{\mathbf{u}}, \mathbf{M P a}$ & Failure Strain, $\varepsilon_{\mathbf{f}}, \mathbf{\%}$ & $\boldsymbol{\lambda}=\left(\varepsilon_{\mathrm{fDNP}}-\varepsilon_{\mathrm{fst}}\right) / \varepsilon_{\mathrm{fst}}{ }^{*} \times \mathbf{1 0 0} \%$ \\
\hline & 1086 & 21.1 & 0 \\
& $42 \mathrm{y}$ & 1092 & 15.9 & -25.02 \\
& $37 \mathrm{y}$ & 1102 & 16.8 & -20.67 \\
& $40 \mathrm{y}$ & 1114 & 17.2 & -18.64 \\
VT23M & $41 \mathrm{y}$ & 1095 & 18.3 & -13.29 \\
& $2 \mathrm{y}$ & 1094 & 21.7 & 2.60 \\
& $7 \mathrm{y}$ & 1093 & 22.3 & 5.39 \\
& $5 \mathrm{y}$ & 1101 & 21.5 & 1.70 \\
& $4 \mathrm{y}$ & 1104 & 19.3 & -8.65 \\
& $3 \mathrm{y}$ & 1115 & 18.9 & -10.79 \\
& $39 \mathrm{y}$ & 1131 & 12.8 & -39.36 \\
\hline
\end{tabular}

${ }^{*} \varepsilon_{\mathrm{fst}}$-failure strain of the specimen during static failure.

A slight increase in plastic deformation was observed only in a narrow range of jumps of plastic deformation $\varepsilon_{\text {imp. }}$. 
It should be noted that curve 33y, which corresponds to static stretching of the specimen in the initial state, and curves $2 y, 5 y$, and $7 y$, which correspond to specimens subjected to the additional impulse loading in the range of jumps of deformation $\varepsilon_{\text {imp }}=0.2-1.0 \%$, are close in shape. However, the resistance of the alloy to deformation at the stage of damage accumulation after the DNP improves significantly (stress-strain diagrams $2 y, 5 y$, and $7 y$ are located above the descending curve 33y). In addition, one should pay attention to the stability of the mechanical properties of the alloy after the impulse introduction of energy into the alloy (stress-strain curves $2 \mathrm{y}, 5 \mathrm{y}$, and $7 \mathrm{y}$ are virtually identical).

Figure 7 presents individual stress-strain diagrams of the investigated specimens from the VT23M alloy and Figure 8 presents some generalized results of experiments on the impact of the impulse introduction of energy into the VT23M alloy within the strain range $\varepsilon=0.025-3.75 \%$ on the general deformation of the alloy with subsequent static stretching (see Table 5).

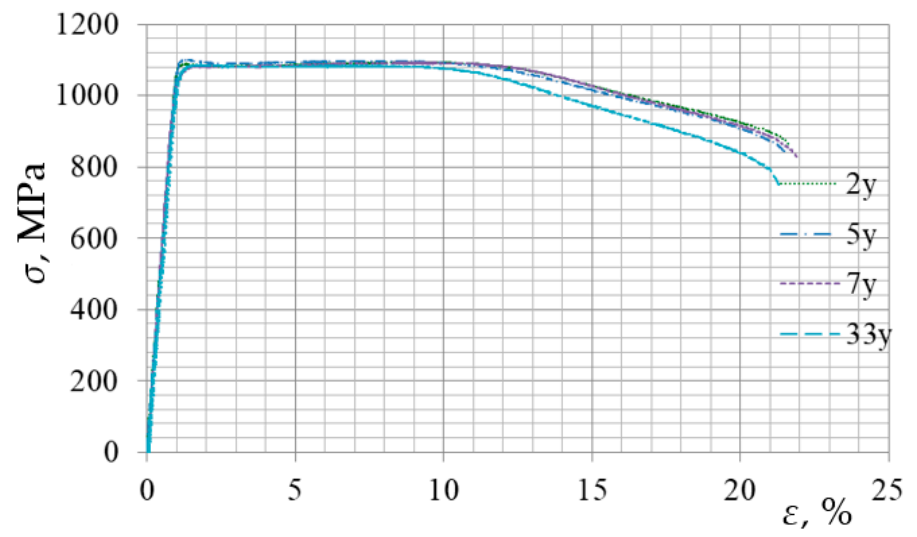

Figure 7. Stress-strain diagrams of the tested specimens from the VT23 alloy (loading schemes are described in Table 5).

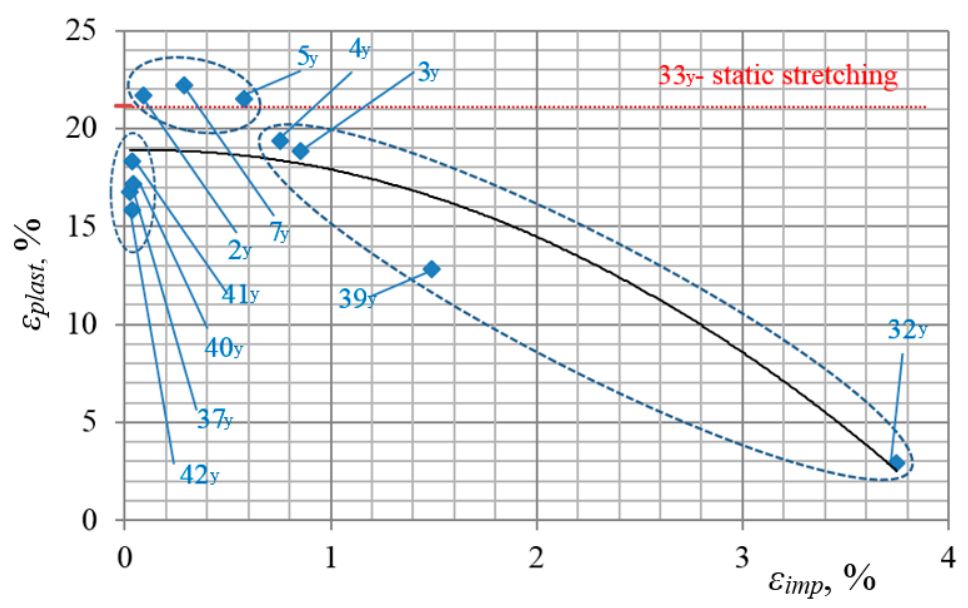

Figure 8. Dependence of plastic deformation of specimens from titanium alloy VT23 under static stretching $\left(\varepsilon_{\text {plast }}\right)$ on impulse deformation $\left(\varepsilon_{\text {imp }}\right)$, obtained under DNP.

\subsubsection{Fractographic Analysis of Failure of the VT23M Alloy}

Fractures of specimens tested under loading schemes 5y and 33y (see Table 2) were compared to reveal certain differences in failure of the VT23M alloy. Fracture surface of specimen 33y was formed by the brittle-ductile mechanism, it was covered with macro-scale band-like striations oriented along the longer edge of the specimen (Figure 9a). The microrelief was formed by shallow dimples with distinct "sharp" boundaries. At a higher resolution, it was established that the material was fractured by the typical viscous mechanism due to the origin and growth of cavities with the dimple relief, which were formed due to the extraction of interstices between them up to rupture (Figure 9b,d). 
However, deformation processes on the boundaries between the dimples show that microplasticity was exhausted fast enough and the boundaries between the dimples were formed by the brittle mechanism. Sharp edges of the dimples indicate the brittle mechanism of failure after the material plasticity was exhausted (Figure 9c). The lateral surfaces of the dimples are smooth and brittle (as if formed by spalling).

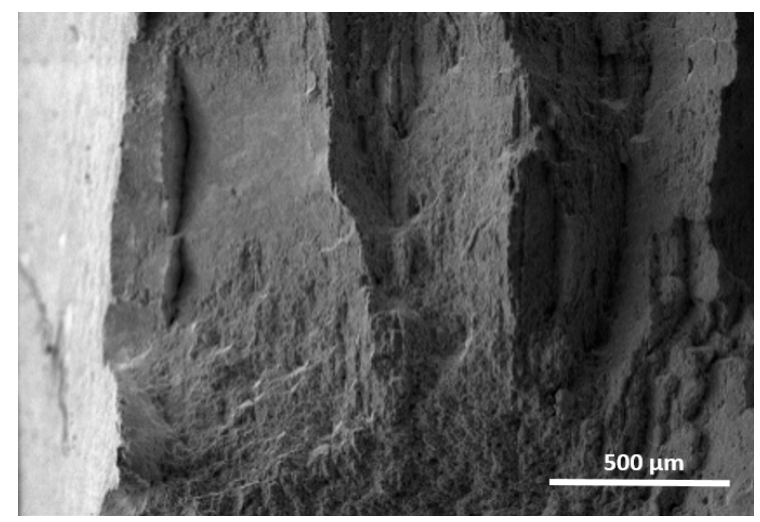

(a)

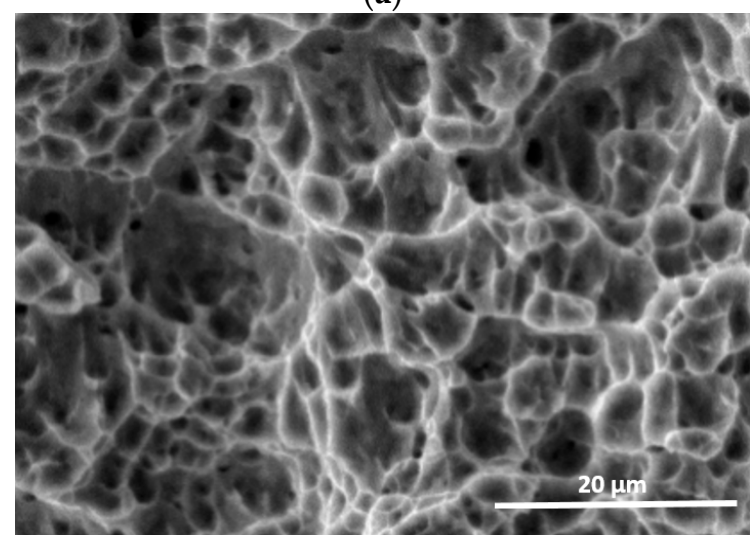

(c)

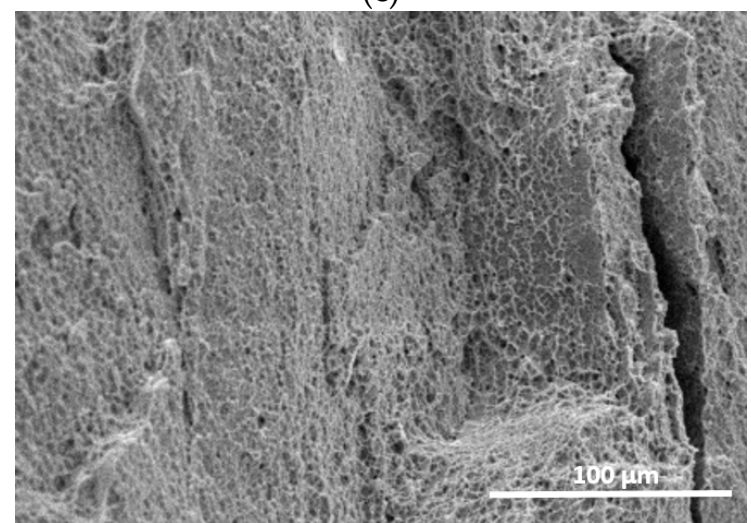

(e)

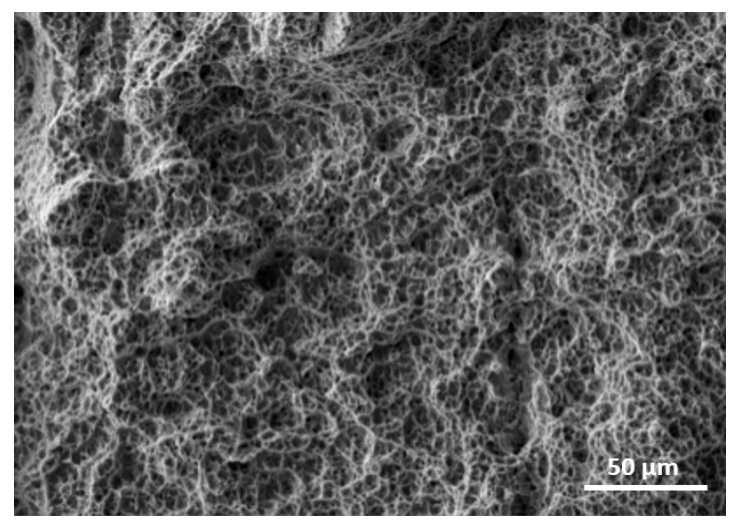

(b)

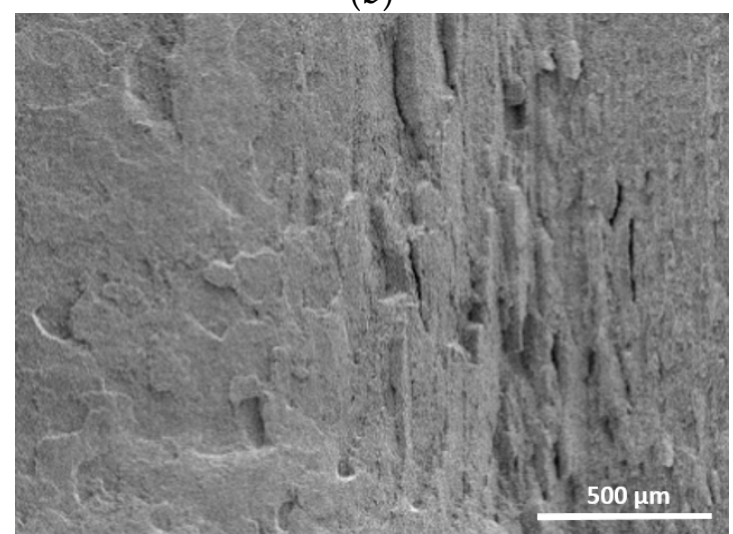

(d)

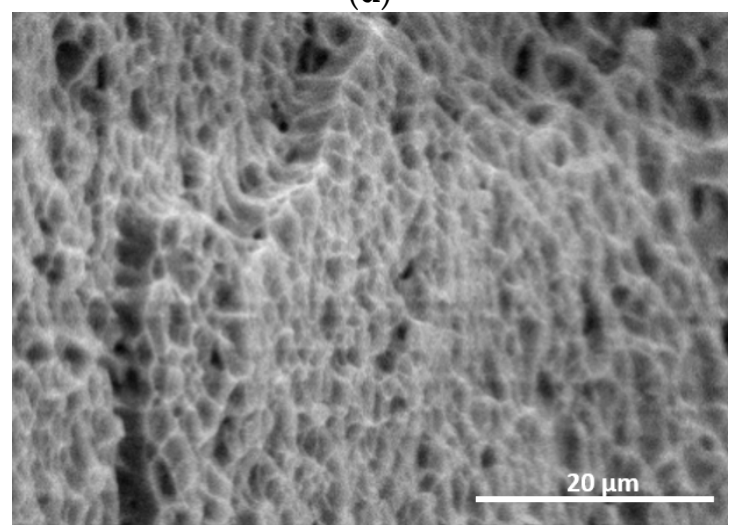

(f)

Figure 9. Fractograms of the fracture surface of the specimen from the VT23M alloy subjected to static stretching, 33y $(\mathbf{a}-\mathbf{c})$ and to DNP, $5 y(\mathbf{d}-\mathbf{f})$.

At the macro level, the fracture surface of specimen 5y is smoothed (Figure 9a), and covered with individual microcracks caused by lamination (Figure 9e). At high magnifications, it can be seen that the surface is covered with small dimples. The specimen surface after the DNP is more uniform and organized, the dimples are smoothed (Figure 9). In addition, it can be seen that dimples have approximately the same size in contrast to deformation scheme $33 \mathrm{y}$, which is characterized 
by dimples on the surface ranging from 2.0 to $12 \mu \mathrm{m}$ in size. The obtained results on the impulse introduction of energy into the VT23M alloy also show that technological improvements of the initial structure of two-phase high-strength titanium alloys reduce the effects that lead to an increase in plastic deformation due to the impulse introduction of energy.

However, this does not mean that other plastic properties of the VT23M alloy do not improve with the impulse introduction of energy. The obtained results on the impulse introduction of energy into the VT23M alloy also show that technological improvements of the initial structure of two-phase high-strength titanium alloys reduce the effects that lead to an increase in plastic deformation due to the impulse introduction of energy.

\subsubsection{Impact Toughness of the VT23M Alloy}

A significant influence of DNP on the impact toughness and crack resistance of the alloy was found. For a comparative evaluation of the effect of DNP on the impact toughness, we made cuts of identical shapes on specimens after the DNP $\left(\varepsilon_{\text {imp }}=0.2-1.0 \%\right)$ with identical levels of plastic deformation under static stretching (Figure 10). Next, the specimens were tested on the impact testing machine PSW-30.

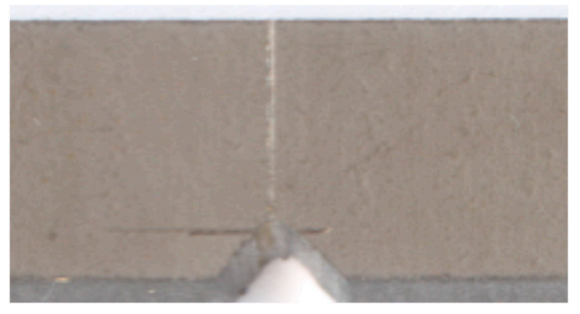

Figure 10. Shape of the cut on a specimen.

The corresponding test results are shown in Figure 11. When comparing the results of the tests, it can be noted that impact toughness of the VT23M alloy after the DNP has increased by at least $20 \%$ (see Figure 11). The fractographic analysis of specimen fractures subjected to impact toughness tests under schemes 33y (Figure 12a-c) and 48y (Figure 12b-d) has been performed. It indicates an improvement in the energy-intensive properties of the alloy after the realization of DNP.

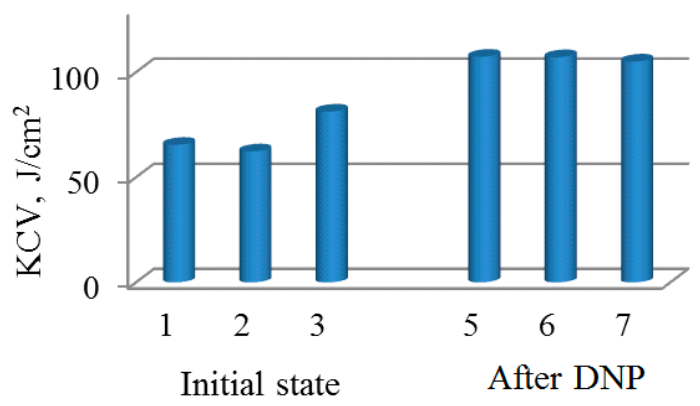

Figure 11. Impact toughness of the VT23M alloy for impact testing in the initial state and after DNP.

The specimen studied by test scheme 33y is characterized by a fibrous fracture surface, i.e., the surface has less roughness and is "smoothed" (Figure 12a). Small, shallow, and equilibrium dimples were formed in the zones with weakened bonds between structural components (Figure 12b,c). The partitions between these dimples were formed by a typical ductile mechanism. The morphological analysis of the fracture surface of specimen No. $48 \mathrm{y}$ indicates a significant effect of shear processes on the formation of a breakage. The central part of the fractures is oriented normally to the propagation direction of the main defect, however, it is bordered on the right and left by sections formed as a result of macro-shear (Figure 12d). A decrease in the size of dimples is noticeable compared to static fracture, 
along with their greater disorder (Figure 12e). The shape of dimples varies from round to elongated, which results from the propagation of the main defect and the stochastic process of coalescence of dimples (Figure 12f).

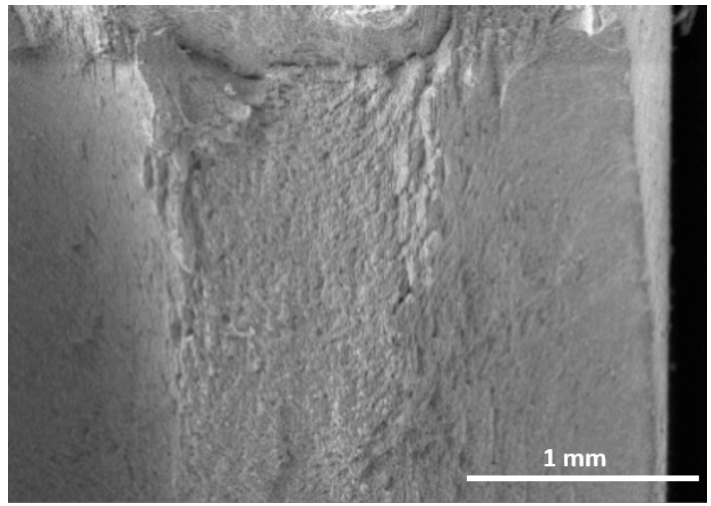

(a)

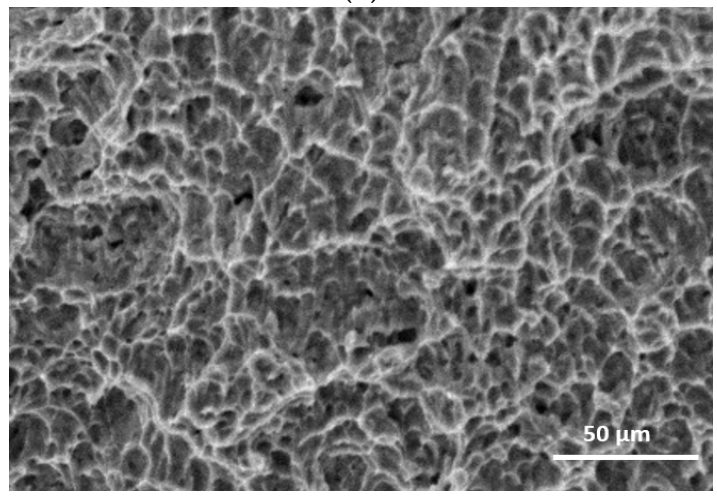

(c)

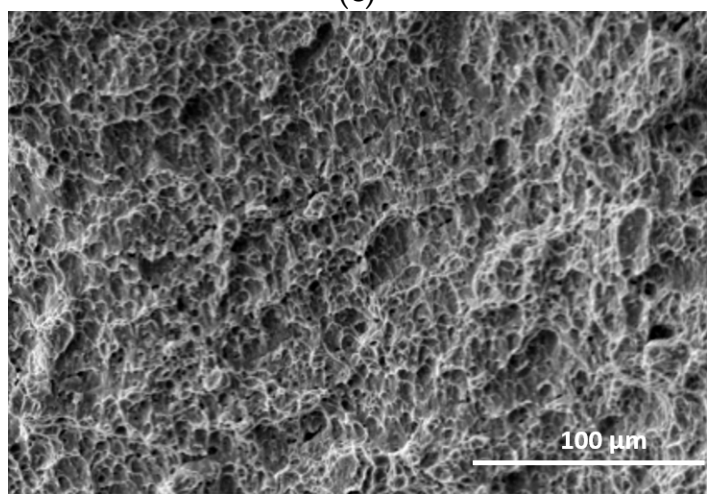

(e)

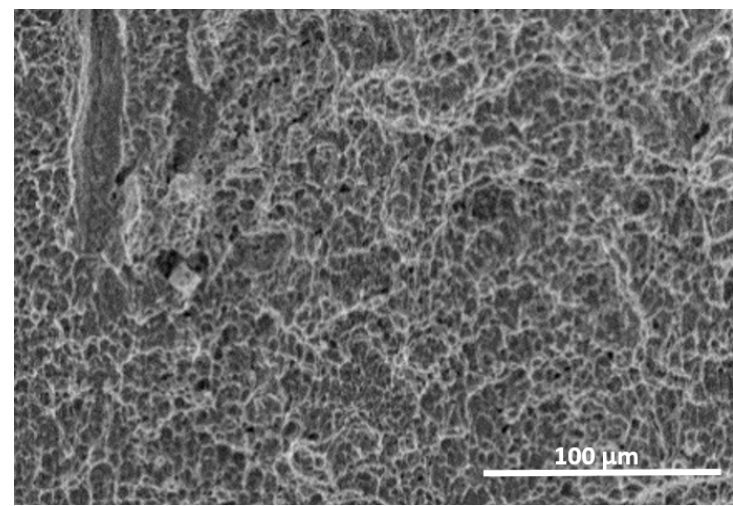

(b)

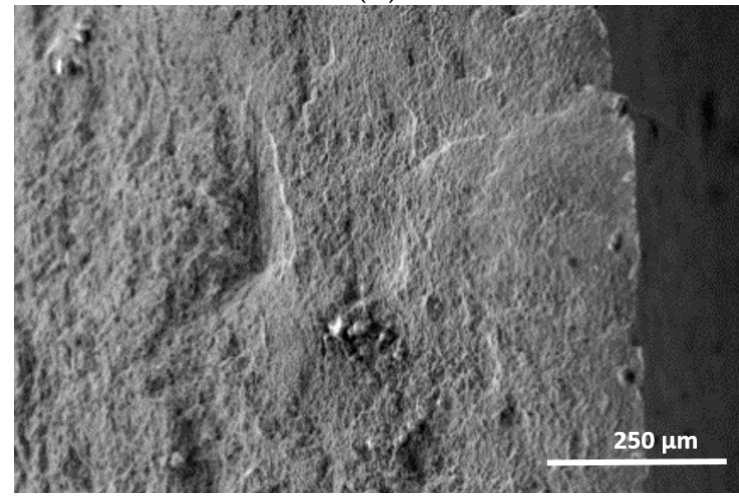

(d)

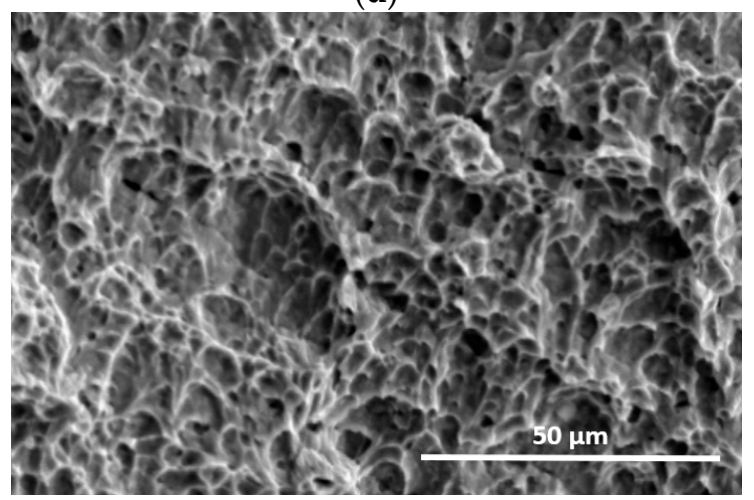

(f)

Figure 12. Fractograms of fractures of specimens from the VT23M alloy subjected to impact toughness tests under schemes $33 \mathrm{y}(\mathbf{a}-\mathbf{c})$ and $48 \mathrm{y}, \varepsilon_{\mathrm{imp}}=0.6 \%(\mathbf{d}-\mathbf{f})$.

The partitions between these sites with dimples of different shapes are formed by a typical ductile mechanism, with the formation of breakouts and deformed sections of the fracture surface. After the realization of DNP, the number of microdefects increases in the alloy, which contributes to the formation of a greater number of micropores, however, their sizes are smaller than those formed under static deformation [35-38]. Significant density of pores contributes to an increase in the energy expenditures for fracture. 


\subsection{Method of Complete Diagrams}

Unfortunately, the use of standard stress-strain diagrams after a complex combined loading mode does not allow us to assess the cracking strength of the material, which is important for practical tasks.

To study the complete set of mechanical properties of titanium alloys subjected to a combined loading mode, including the characteristics of crack resistance, a new method for investigating the material fracture kinetics, the so-called method of complete stress-strain diagrams, was used in this research. In this paper, the authors do not use "true" stress-strain diagrams, since when testing flat specimens from plastic materials, it is hard to define the actual cross-sectional area of the specimen at the time of the macrocrack start. This is due to the different values of the local plastic strains of the specimen in three directions of deformation. These features are analyzed in detail in $[39,40]$.

This method was theoretically and experimentally substantiated by Lebedev and Chausov $[39,40]$. They were the first to develop a new criterion of crack resistance $K_{\lambda}$ based on the analysis of complete stress-strain diagrams.

$$
K_{\lambda}=\sqrt{S_{k} \cdot \overline{\Delta l}_{p} \cdot E}
$$

Here, $S_{k}$ is the actual resistance of the material to tearing; $\overline{\Delta l_{p}}$ is the specimen elongation at the growth stage of the separating macrocrack normalized to the cross-sectional area of the standard specimen; $E$ is the Young's modulus of materials.

When implementing a complete stress-strain diagram, the stability of the processes of deformation and fracture of materials is provided at all stages, including the stage of the formation and growth of the macrocrack in the material [41-43].

It is very essential that when using the method of complete stress-strain diagrams, all the complex combined loading operations are performed on the same standard small-size specimens, and the same specimens are finally evaluated for changes in the mechanical properties of titanium alloys under subsequent static stretching, including the characteristics of crack resistance.

In the process of recording complete stress-strain diagrams of sheet materials, various micromechanisms of fracture associated with the formation of an internal separating macrocrack in the sheet material occurred, which protrudes to the lateral surface of the sheet material leading to the formation of a through macrocrack that propagates across the width of the specimen [40]. Therefore, there appeared to be some difficulties in identifying the self-similar growth of the separating macrocrack [41].

Thus, the authors have improved the technique of studying the crack growth in sheet materials using the method of complete stress-strain diagrams [41-43]. In the proposed method, the technical possibility of providing the continuity of the fracture micromechanism of the titanium alloy by type I + III is ensured by making identical central circular holes in specimens (Figure 1b). In this case, the self-similar growth of the macrocrack is provided by the mixed type (I + III) [44-47]. At the same time, the initial, almost straight descending sections are recorded on complete stress-strain diagrams. In this case, the impact of the impulse introduction of energy into the material on the static crack resistance is evaluated with an absolutely identical mixed type (I + III). Since in real sheet structures with sufficiently long macrocracks this is one of the main types of fracture, the proposed method allows to reliably estimate a change in energy expenditure for the crack propagation by type (I + III) depending on any complex combined loading compared to static stretching. Thus, taking into account a change in the inclination of the straight descending branch of the stress-strain diagram, one can unequivocally state a change in the crack resistance of a particular sheet material depending on the temperature-force loading conditions, compared with the standard static stretching (Figure 13). Since in the process of testing under this technique the "necks" are practically not formed in specimens from sheet two-phase high-strength titanium alloys, and the macrocrack starts in the alloy in conditions of low plastic deformation, it is easier to use value $\sigma_{k}=F_{k} / A_{0}$ instead of value $S_{k}$ in Equation (2), where $F_{k}$ is the load applied to the specimen at the time of the macrocrack start in the alloy, $A_{0}$ is the initial cross-sectional area of the specimen from the alloy. 


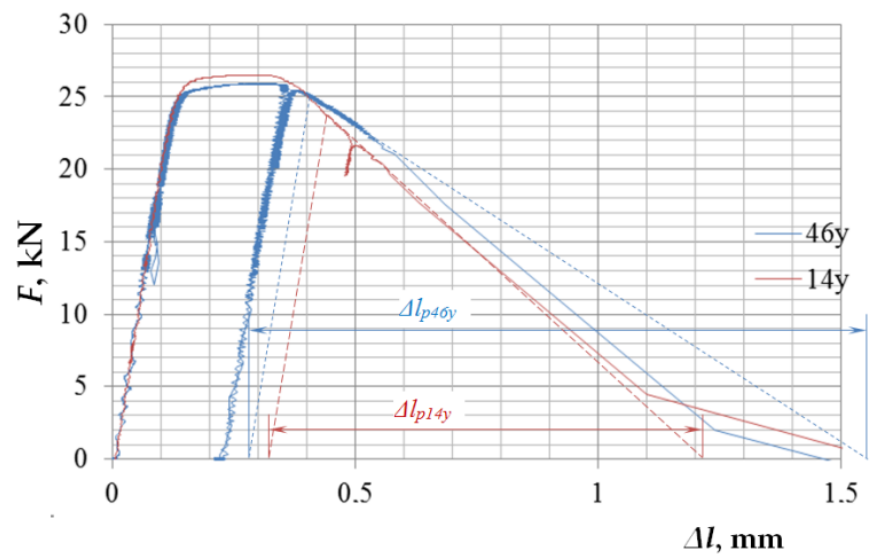

Figure 13. Complete stress-strain diagrams of specimens from the VT23M alloy in different states: 14y, in the initial state; 46 , after $\operatorname{DNP}\left(\varepsilon_{\text {imp }}=2.2 \%\right)$.

Table 6 presents the data on determining the crack resistance $K_{\lambda}$ for the VT23M alloy in the initial state (sc. of loading No. 14y) and after DNP (sc. of loading No. 46y). The analysis of the data shows that after the realization of DNP, an increase in the crack resistance of the VT23M alloy to 13-19\% is noted.

Table 6. Value of crack resistance parameter $K_{\lambda}$ for the VT23M alloy in different states.

\begin{tabular}{ccccc}
\hline Scheme of Loading & $\overline{\Delta l_{p}}, \mathbf{m m}$ & $\boldsymbol{\sigma}_{\boldsymbol{k}}, \mathbf{M P a}$ & $\boldsymbol{E}, \mathrm{GPa}$ & $\boldsymbol{K}_{\boldsymbol{\lambda}} \mathbf{M P a} \sqrt{ } \boldsymbol{m}$ \\
\hline $46 \mathrm{y}$ & 1.24 & 1102.7 & 120 & 405.7 \\
$14 \mathrm{y}$ & 0.90 & 1089.5 & 112 & 331.8 \\
\hline
\end{tabular}

The completed set of experimental studies confirmed the positive effect of the impulse introduction of energy on the improvement of the plastic properties of sheet high-strength two-phase titanium alloys VT23 and VT23M. It should be emphasized that the use of impact-oscillatory loading practically does not lead to a marked decrease in the strength properties of the alloy.

\section{Conclusions}

A simple technological method is proposed and tested experimentally, which allows improving the mechanical properties of sheet two-phase high-strength titanium alloys VT23 and VT23M on the finished product (rolled metal) due to impact-oscillatory loading.

It is shown that plastic properties of two-phase high-strength titanium alloys VT23 and VT23M are very sensitive to the effects of impact-oscillatory loading with a loading frequency of $1-2 \mathrm{kHz}$, in which dynamic non-equilibrium processes with self-organization of the structure are realized in the alloys. The assumption that the positive or negative effect of DNP on changes in the plastic properties of two-phase titanium alloys are due to impact-oscillatory loading, which depends first and foremost on the initial parameters of the structure of the titanium alloy. In particular, the best effects to increase the plastic properties due to impact-oscillatory loading are realized on the VT23 alloy with a higher initial content of the plastic $\beta$-phase.

It is established that under optimal modes of impact-oscillatory loading it is possible to increase the ductility of the VT23 alloy by $30-35 \%$, that of the VT23M alloy by 5\%, and also to improve the impact toughness of the VT23M alloy by $20 \%$ and increase the crack resistance of the VT23M alloy by $13-19 \%$.

Of particular importance is the fact that all the detected effects to improve the plastic properties of the investigated titanium alloys due to impact-oscillatory loading were recorded at a room temperature. 
Author Contributions: Conceptualization, M.C.; Formal analysis, J.B. and A.G.; Investigation, M.C., J.B., A.P., P.M., L.T., and A.G.; Methodology, M.C. and A.P.; Project administration, P.M.; Validation, P.M, M.C., A.P., and J.B.; Writing—original draft, P.M., M.C., J.B., A.P., and A.G.; Writing—review and editing, L.T.

Funding: This research was funded by Ministry of Education of the Slovak Republic VEGA No. 1/0424/17 and of the Slovak Research and Development Agency APVV-16-0359 and the APC was funded by Slovak Research and Development Agency.

Acknowledgments: This work was supported by scientific grant agency of the Ministry of Education of the Slovak Republic VEGA No. 1/0424/17 and of the Slovak Research and Development Agency APVV-16-0359.

Conflicts of Interest: The authors declare no conflict of interest.

\section{References}

1. Peters, M.; Kumpfert, J.; Ward, C.H.; Leyens, C. Titanium alloys for aerospace applications. Adv. Eng. Mater. 2003, 5, 419-427. [CrossRef]

2. Khanna, N.; Davim, J.P. Design-of-experiments application in machining titanium alloys for aerospace structural components. Measurement 2015, 61, 280-290. [CrossRef]

3. Brewer, W.D.; Bird, R.K.; Wallace, T.A. Titanium alloys and processing for high speed aircraft. Mater. Sci. Eng. A 1998, 243, 299-304. [CrossRef]

4. Khorev, A.I. High-strength titanium alloy VT23 and its applications in advanced welded and brazed structures. Weld. Int. 2010, 24, 276-281. [CrossRef]

5. Khorev, A.I. Alloying titanium alloys with rare-earth metals. Russ. Eng. Res. 2011, 31, 1087-1094. [CrossRef]

6. Brezinová, J.; Hudák, R.; Guzanová, A.; Draganovská, D.; Ižaríková, G.; Koncz, J. Direct metal laser sintering of Ti6Al4V for biomedical applications: Microstructure, corrosion properties, and mechanical treatment of implants. Metals 2016, 6, 171. [CrossRef]

7. Guzanová, A.; Ižaríková, G.; Brezinová, J.; Živčák, J.; Draganovská, D.; Hudák, R. Influence of build orientation, heat treatment, and laser power on the hardness of Ti6Al4V manufactured using the DMLS process. Metals 2017, 7, 318. [CrossRef]

8. Illarionov, A.G.; Popov, A.A.; Illarionova, S.M. Effect of microalloying, with rem inclusively, on the structure, phase composition and properties of $(\alpha+\beta)$-titanium alloy. Metal Sci. Heat Treat. 2016, 57, 719-725. [CrossRef]

9. Gordienko, A.I.; Dymovskii, A.S.; Kozina, I.Y. Correlation of grain-structure parameters with the properties of thermally strengthened titanium alloys VT6 and VT23. Metal Sci. Heat Treat. 1991, 33, 137-141. [CrossRef]

10. Babareko, A.A.; Egiz, I.V.; Khorev, M.A. Effect of supplementary alloying of titanium alloy VT23 on its phase composition and tendency to recrystallization. Metal Sci. Heat Treat. 1993, 35, 116-120. [CrossRef]

11. Nikiforov, Y.; Yakovyna, V.; Berchenko, N. Laser shock waves as a tool of changing the strains in materials. Mater. Sci. Eng. A 2000, A288, 173-176. [CrossRef]

12. Lovinger, Z.; Rikanati, A.; Rosenberg, Z.; Rittel, D. Electro-magnetic collapse of thick-walled cylinders to investigate spontaneous shear localization. Int. J. Impact Eng. 2011, 38, 918-929. [CrossRef]

13. Tiamiyu, A.A.; Eskandari, M.; Nezakat, M.; Wang, X.; Szpunar, J.A.; Odeshi, A.G. A comparative study of the compressive behaviour of AISI 321 austenitic stainless steel under quasi-static and dynamic shock loading. Mater. Des. 2016, 112, 309-319. [CrossRef]

14. Chausov, N.G.; Voityuk, D.G.; Pilipenko, A.P.; Kuz'menko, A.M. Setup for testing materials with plotting complete stress-strain diagrams. Strength Mater. 2004, 36, 532-537. [CrossRef]

15. Chausov, N.G.; Pilipenko, A.P. Laws of deformation processes and fracture of plastic steel from the point of view of dynamic overloading. Mechanika 2005, 54, 24-29. Available online: http:/ / www.mechanika.ktu.lt/ index.php/Mech/article/viewFile/14476/7477 (accessed on 10 January 2019).

16. Chausov, M.G.; Berezin, V.B.; Pylypenko, A.P.; Hutsaylyuk, V.B. Strain field evolution on the surface of aluminum sheet alloys exposed to specific impact with oscillation loading. J. Strain. Anal. 2014, 50, 61-62. [CrossRef]

17. Hutsaylyuk, V.; Chausov, M.; Berezin, V.; Pylypenko, A. Strength analysis of mechanical systems at dynamic non-equilibrium processes. Eng. Fail. Anal. 2013, 35, 636-644. [CrossRef]

18. Zasimchuk, E.; Markashova, L.; Baskova, O.; Turchak, T.; Chausov, N.; Hutsaylyuk, V.; Berezin, V. Influence of combined loading on microstructure and properties of aluminum alloy 2024-T3. J. Mater. Eng. Perfom. 2013, 22, 3421-3429. [CrossRef] 
19. Zasimchuk, E.E.; Markashova, L.I.; Tutchak, T.V.; Chausov, N.G.; Pylypenko, A.P.; Paratsa, V.N. Peculiarities of structural transformation in plastic materials under abrupt changes in loading conditions. Phys. Mesom. 2009, 12, 175-179. [CrossRef]

20. Zasimchuk, E.; Turchak, T.; Baskova, A.; Chausov, N.; Hutsaylyuk, V. Structural transformations in metallic materials during plastic deformation. J. Mater. Eng. Perfom. 2017, 26, 1293-1299. [CrossRef]

21. Chausov, M.G.; Pylypenko, A.P.; Berezin, V.B.; Markashova, L.I.; Kushnariova, O.S.; Hutsaylyuk, V.B. Influence of impact-oscillatory loading upon the mechanical properties of the VT-22 titanium alloy sheet. J. Mater. Eng. Perfom. 2016, 25, 3482-3492. [CrossRef]

22. Chausov, M.; Maruschak, P.; Pylypenko, A.; Markashova, L. Enhancing plasticity of high-strength titanium alloys VT22 under impact-oscillatory loading. Phil. Mag. 2017, 97, 389-399. [CrossRef]

23. Chausov, M.G.; Maruschak, P.O.; Pylypenko, A.P.; Berezin, V.B.; Prentkovskis, O. Structural self-organization of titanium alloys under impulse force action. Mater. Test. 2017, 59, 567-569. [CrossRef]

24. ASTM E8M-04, 2004. Standard Test Methods for Tension Testing of Metallic Materials; ASTM International: West Conshohocken, PA, USA, 2004; Available online: www.astm.org (accessed on 10 January 2019).

25. March, A. Mathematische theorie der regelung nach der korngestalt bei affiner deformation. Z. Kristallogr. 1932, 81, 285-297. (In German) [CrossRef]

26. Dollase, W.A. Correction of intensities for preferred orientation of the March model. J. Appl. Cryst. 1986, 19, 267-272. [CrossRef]

27. Brooks, C.R.; Choudhury, A. Metallurgical Failure Analysis; McGraw-Hill: New York, NY, USA, 1993; 409p.

28. Boyer, R.; Welsch, G.; Collings, E.W. (Eds.) Materials Properties Handbook: Titanium Alloys; ASM International: Materials Park, OH, USA, 1994; 1169p.

29. Meyers, M.A. Dynamic Behavior of Materials; John Wiley \& Sons, Inc.: New York, NY, USA, 1994; 688p.

30. Panin, S.V.; Maruschak, P.O.; Vlasov, I.V.; Ovechkin, B.B. Impact toughness of 12Cr1MoV steel. Part 1 -Influence of temperature on energy and deformation parameters of fracture. Theor. Appl. Fract. Mech. 2016, 83, 105-113. [CrossRef]

31. Panin, S.V.; Maruschak, P.O.; Vlasov, I.V.; Sergeev, V.P.; Ovechkin, B.B.; Neifeld, V.V. Impact toughness of $12 \mathrm{Cr} 1 \mathrm{MoV}$ steel. Part 2-Influence of high intensity ion beam irradiation on energy and deformation parameters and mechanisms of fracture. Theor. Appl. Fract. Mech. 2016, 83, 83-92. [CrossRef]

32. Gusev, A.I.; Rempel, A.A. Nanocrystalline Materials; Cambridge International Science Publishing: Cambridge, UK, 2004; 351p.

33. Chausov, M.; Pylypenko, A.; Berezin, V.; Volyanska, K.; Maruschak, P.; Hutsaylyuk, V.; Markashova, L.; Nedoseka, S.; Menou, A. Influence of dynamic non-equilibrium processes on strength and plasticity of materials of transportation systems. Transport 2018, 33, 231-241. [CrossRef]

34. Chausov, M.; Maruschak, P.; Prentkovskis, O.; Karpets, M. Risks Associated with the Use of High-Strength Titanium Alloys in Transportation Systems. In Reliability and Statistics in Transportation and Communication; RelStat 2017. Lecture Notes in Networks and Systems; Kabashkin, I., Yatskiv, I., Prentkovskis, O., Eds.; Springer: New York, NY, USA, 2018; Volume 36, pp. 213-220.

35. Chausov, M.G.; Maruschak, P.O.; Pylypenko, A.P.; Berezin, V.B. Features of Deformation and Fracture of Plastic Materials under Impact-Oscillatory Loading; Terno-Graf: Ternopil, Ukraine, 2018; 288p. (In Ukrainian)

36. Maruschak, P.; Konovalenko, I.; Chausov, M.; Pylypenko, A.; Panin, S.; Vlasov, I.; Prentkovskis, O. Impact of dynamic non-equilibrium processes on fracture mechanisms of high-strength titanium alloy VT23. Metals 2018, 8, 983. [CrossRef]

37. Konovalenko, I.V.; Maruschak, P.O. Application of the properties of fuzzy sets in the computer analysis of the shapes and sizes of tear pits. Mater. Sci. 2018, 53, 548-559. [CrossRef]

38. Chausov, M.; Maruschak, P.; Pylypenko, A.; Prentkovskis, O.; Hutsaylyuk, V. Modification of the mechanical properties of the sheet two-phase high-strength titanium alloy VT23 due to impulse introduction of energy. Procedia Eng. 2017, 187, 414-419. [CrossRef]

39. Chausov, N.G.; Lebedev, A.A. Fracture mechanism in plastic sheet materials. Strength Mater. 2003, 35, 327-333. [CrossRef]

40. Lebedev, A.A.; Chausov, N.G. Phenomenological fundamentals of the evaluation of crack resistance of materials on the basis of parameters of falling portions of strain diagrams. Strength Mater 1983, 15, 155-160. [CrossRef] 
41. Chausov, M.G.; Pylypenko, A.P.; Maruschak, P.O. A Method for the Improvement of Plastic Properties of Sheet Two-Phase High.-Strength Titanium Alloys Caused by Impact Vibration Loading: Scientific and Methodical Recommendations for the Ukrainian Plants for the Design of Production of Agricultural Equipment; Ternopil FOP V. A.: Palyanytsya, Ukraine, 2017; 48p, (In Ukrainian). Available online: http:/ / elartu.tntu.edu.ua/handle/lib/ 22618 (accessed on 10 January 2019).

42. Maruschak, P.; Sorochak, A.; Brezinová, J.; Guzanová, A.; Yasnii, O. Micromechanisms of ferrite-pearlite steels fracture under cyclic and impact loading. Acta Metall. Slov. 2017, 23, 345-355. [CrossRef]

43. Chausov, M.G.; Pylypenko, A.P.; Maruschak, P.O.; Dovganyuk, V.A. A method of estimating pulsed input of energy into plastic material. Patent of Ukraine No. 113940, 27 March 2017. (In Ukrainian). Available online: http://uapatents.com/6-113940-sposib-ocinki-impulsnogo-vvedennyaenergi-v-plastichnijj-material.html (accessed on 10 January 2019).

44. Panin, S.V.; Moiseenko, D.D.; Maksimov, P.V.; Vlasov, I.V.; Byakov, A.V.; Maruschak, P.O.; Berto, F.; Schmauder, S.; Vinogradov, A. Influence of energy dissipation at the interphase boundaries on impact fracture behaviour of a plain carbon steel. Theor. Appl. Fract. Mech. 2018, 97, 478-499. [CrossRef]

45. Du, Y.; Mol'kov, Y.V.; Lenkovs'kyi, T.M.; Koval'chuk, R.A. Analysis of the stress-strain state of the process zone of a plate with central crack under biaxial loading. Mater. Sci. 2017, 53, 86-92. [CrossRef]

46. Konovalenko, I.V.; Maruschak, P.O.; Chernets, V.S.; Chertkov, M.V. Development of the automated method for identifying the parameters of dimples of ductile tearing on the fracture surface of high-strength titanium alloys. In Proceedings of the 6th Scientific and Technical Conference "Information Models, Systems and Technologies", Ternopil, Ukraine, 12-13 December 2018.

47. Zagulyaev, D.V.; Konovalov, S.V.; Yaropolova, N.G.; Ivanov, Y.F.; Komissarova, I.A.; Gromov, V.E. Effect of the magnetic field on the surface morphology of copper upon creep fracture. J. Surf. Invest. X-ray Synchrotron Neutron Techn. 2015, 9, 410-414. [CrossRef]

(C) 2019 by the authors. Licensee MDPI, Basel, Switzerland. This article is an open access article distributed under the terms and conditions of the Creative Commons Attribution (CC BY) license (http:/ / creativecommons.org/licenses/by/4.0/). 